Abstracta Iranica Abstracta Iranica

Revue bibliographique pour le domaine irano-aryen

Volume 23 | 2002

Comptes rendus des publications de $\mathbf{2 0 0 0}$

\title{
Essays on Zarathustra and Zoroastrianism. Translated and Edited by Prods Oktor Skjaervøm, Costa Mesa, Mazda Publishers Inc., 2000, XVI-131 p.
}

\section{Rédaction}

\section{(2) OpenEdition}

Journals

Édition électronique

URL : http://journals.openedition.org/abstractairanica/35464

DOI : 10.4000/abstractairanica.35464

ISSN : 1961-960X

Éditeur :

CNRS (UMR 7528 Mondes iraniens et indiens), Éditions de l'IFRI

Édition imprimée

Date de publication : 15 mai 2002

ISSN : 0240-8910

Référence électronique

Rédaction, «Essays on Zarathustra and Zoroastrianism. Translated and Edited by

Prods Oktor Skjaervøm, Costa Mesa, Mazda Publishers Inc., 2000, XVI-131 p. », Abstracta Iranica [En

ligne], Volume 23 | 2002, document 184, mis en ligne le 08 février 2010, consulté le 25 septembre

2020. URL : http://journals.openedition.org/abstractairanica/35464; DOI : https://doi.org/10.4000/

abstractairanica.35464

Ce document a été généré automatiquement le 25 septembre 2020.

Tous droits réservés 


\title{
Essays on Zarathustra and
} Zoroastrianism. Translated and Edited by Prods Oktor Skjaervøm, Costa Mesa, Mazda Publishers Inc., 2000, XVI-131 p.

\author{
Rédaction
}

Après l'avant-propos de l'éditeur s'expliquant sur sa traduction (XI-XII) et la préface de l'auteur situant chacune des parties du livre (XIII-XVI), on trouvera les documents suivants, réunis dans l'ouvrage : Pp. 1-24 : «Characters of Ancient Mazdaism » (1987), 1 ère édition dans History and Anthropology, 3 (1987), pp. 239-262. Pp. 25-30: « Achaemenid Religion: Preliminary Questions». Traduction de "Questions préalables », in : Jean Kellens, éd., La religion iranienne à l'époque achéménide, Iranica Antiqua, Suppl. 5, Gent, 1991, pp. 81-86. Pp. 31-94: "Zarathustra and the Old Avesta, Four Lectures at the Collège de France ». Traduction anglaise du même, texte français paru dans les Travaux de l'Institut d'Etudes Iraniennes, Paris, 1991. Lecture I. «The Text », pp. 31-47. Lecture II. " The Gods ", pp. 48-62. Lecture III. « The Liturgy », pp. 63-80. Lecture IV. «The Men », pp. 81-94. Pp. 95-98: "Yima and Death». Traduction anglaise du texte paru dans Languages and Cultures, Studies in Honor of Edgart C. Pélomé, M. A. Jazayery and W. Winter, eds., Mouton de Gruyter, 1988, pp. 329-34. Pp. 99-112: "The Speculative Ritual in Ancient Mazdaism ». Traduction anglaise du texte paru dans Archives Sociales des Religions, 85 (1994), pp. 45-67. Pp. 114-131 : Bibliographies. 
INDEX

Thèmes : 6.1. Zoroastrisme

\section{AUTEURS}

RÉDACTION

Directeur de la revue et secrétariats (Paris et Téhéran) 